Full length article

\title{
Nafion phosphonic acid composite membranes for proton exchange membranes fuel cells
}

\author{
Fátima C. Teixeira ${ }^{a}$, Ana I. de Sá ${ }^{a}$, António P.S. Teixeira ${ }^{b}$, C.M. Rangel ${ }^{a, *}$ \\ ${ }^{a}$ Laboratório Nacional de Energia e Geologia, I.P., Estrada do Paço do Lumiar, 22, 1649-038 Lisboa, Portugal \\ ${ }^{\mathrm{b}}$ Departamento de Química, Escola de Ciências e Tecnologia \& Centro de Química de Évora, IIFA, Universidade de Évora, R. Romão Ramalho, 59, 700o-671 Évora, \\ Portugal
}

\section{A R T I C L E I N F O}

\section{Keywords:}

Proton exchange membranes

Fuel cells

Nafion

Phosphonic acids

Proton conductivity

\begin{abstract}
A B S T R A C T
In this work, new doped Nafion membranes with enhanced proton conductivity were prepared to be used as proton exchange membranes in fuel cells. New dopants derived from arylmono- or bisphosphonic acid were prepared and incorporated into the new membranes using impregnation or casting methods. Proton conductivities were assessed by Electrochemical Impedance Spectroscopy (EIS), at different temperatures and relative humidity $(\mathrm{RH})$ conditions, in order to evaluate the influence of the structure and the method of the preparation on proton transport. The membranes prepared by casting showed higher proton conductivities than commercial Nafion membrane at all temperatures and relative humidity conditions studied. The [1,4-phenylenebis(hydroxymethanetriyl)]tetrakis(phosphonic acid) (BP2) showed the best proton conductivity with a value of $87 \mathrm{mS} \mathrm{cm}^{-1}$. The values obtained for the activation energy $\left(E_{a}\right)$ for proton conduction suggests that transport occurs via both Grotthuss and vehicular mechanisms.
\end{abstract}

\section{Introduction}

In today's world, there is an increasing consumption of energy. Traditionally, man is using vast quantities of energy from sources that are closer and easier to obtain. These sources are usually of non-renewable character, with finite reserves and, cumulatively, they are the cause of various civilizational problems, in particular, environmental problems. Therefore, in order to improve the use of planetary resources, there is an enormous need to study and develop new forms of energy generation, in particular introducing sustainable energy technologies, preventing the exhaustion of current energy sources and the prevailing environmental problems [1].

Sustainable energy strategies and technologies based on renewable energy include the introduction of hydrogen and fuel cells playing a pivotal, substantial role. Fuel cells are electrochemical devices that convert the chemical energy of a fuel, usually hydrogen, into electrical energy. This direct and efficient energy conversion, without the formation of intermediates or the production of toxic gases or byproducts, makes the fuel cells technology a promising source of clean energy. Among the fuel cells, the proton exchange membrane fuel cells (PEMFCs) are considered promising power sources, due to their high power density and high power-to-weight ratio [2-14].

Proton exchange membranes are considered a key component for the operation of these fuel cells. The membranes must possess chemical and structural stability, with low permeability to fuel and oxidant and high proton conductivity. Usually, the membranes are made of organic polymers containing acidic functionalities (e.g., sulfonic, carboxylic and phosphonic acid groups), but their proton conduction properties are generally related to the presence of a conducting electrolyte and strongly depend on their water content, which limit their operation temperatures [2-14].

The most studied and used are Nafion membranes, a hydrophobic perfluorosulfonated polymer, with excellent chemical stability and high proton conductivity, with sulfonic acid groups capable of donating protons. However, it requires water for proton conduction, limiting its use to $80^{\circ} \mathrm{C}$ [15-21].

These limitations have fostered the interest in research and development for new alternative membranes, with higher proton conductivity. Most of the early membranes rely on sulfonic acid groups as proton carriers, but it has been found that proton transfer by phosphonic acid group has a lower energy penalty $\left(37.2 \mathrm{~kJ} \mathrm{~mol}^{-1}\right)$ than sulfonic acid groups $\left(69.9 \mathrm{~kJ} \mathrm{~mol}^{-1}\right)$. Also, via its self-ionization, the phosphonic acid group can share both proton donor and acceptor properties, enhancing proton conductivity through the membrane. This has promoted the use of phosphonic acid groups as proton conductors on PEMs [22-30].

\footnotetext{
* Corresponding author.

E-mail address: carmen.rangel@lneg.pt (C.M. Rangel).
} 